\title{
O DIREITO À CIDADE INTELIGENTE SOB A PERSPECTIVA DO DESENVOLVIMENTO SUSTENTÁVEL: O CASO DA AGENDA TERESINA 2030 E DO OBSERVATÓRIO DA MOBILIDADE
}

\section{THE RIGHT TO THE SMART CITY UNDER THE SUSTAINABLE DEVELOPMENT PERSPECTIVE: THE CASE OF 'AGENDA TERESINA 2030' AND THE MOBILITY OBSERVATORY}

\author{
Patricia Borba Vilar Guimarães ${ }^{1}$ \\ Sérgio Alexandre de Moraes Braga Júnior ${ }^{2}$ \\ Thaisi Leal Mesquita de Lima ${ }^{3}$
}

\section{RESUMO}

O direito à cidade é objeto de discussão há mais de cinquenta anos, o que possibilitou um amplo debate sobre quais são os direitos básicos que envolvem o estudo dessa garantia. Após quase meio século, o tema tem sofrido forte impacto, principalmente em razão das inovações que emergiram nas últimas décadas, em especial após o advento da tecnologia. Nesse sentido, urge estudar o fenômeno das cidades inteligentes como parte integrante do direito à cidade, ao passo que o

\footnotetext{
${ }^{1}$ Doutora em Recursos Naturais pela Universidade Federal de Campina Grande (2010). Mestre em Direito pela Universidade Federal do Rio Grande do Norte (2008). Mestre pelo Programa Interdisciplinar em Ciências da Sociedade, na área de Políticas Sociais, Conflito e Regulação Social, pela Universidade Estadual da Paraíba (2002). Bacharel em Direito pela Universidade Estadual da Paraíba (1997). Tecnóloga em Processamento de Dados pela Universidade Federal da Paraíba (1989). É Advogada e Professora da Universidade Federal do Rio Grande do Norte, no Departamento de Direito Processual e Propedêutica (DEPRO). Líder da Base de pesquisa em Direito e Desenvolvimento (UFRN-CNPq). Docente vinculada ao Programa de Pós-graduação em Direito (UFRN-Mestrado Acadêmico) e ao Programa de Pós-graduação em Gestão de Processos Institucionais (UFRNMestrado Profissional. Universidade Federal do Rio Grande do Norte - UFRN - Brasil. ORCID: https://orcid.org/0000-0001-9130-3901 Lattes: http://lattes.cnpq.br/3134219236556237 E-mail: patriciaborb@gmail.com

${ }^{2}$ Doutor em Direito pela Universidade Federal de Pernambuco (2005). Mestre em Direito (Direito e Desenvolvimento) pela Universidade Federal do Ceará (1998). Bacharel em Direito pela Universidade Federal do Ceará (1995). Professor titular da Universidade do Estado do Rio Grande do Norte (UERN) e Professor Associado I da Universidade Federal do Rio Grande do Norte (UFRN). Atua como Coordenador Operacional do Doutorado Interinstitucional (DINTER) em Direito da Universidade do Estado do Rio Grande do Norte (UERN) em convênio com a Universidade Federal do Paraná (UFPR). Universidade do Estado do Rio Grande do Norte - UERN - Brasil Lattes: http://lattes.cnpq.br/8429436981406857 E-mail: s.alexandre.prof@gmail.com

${ }^{3}$ Bacharel em Direito pela Universidade Federal do Rio Grande do Norte. Mestre em Direito pela Universidade Federal do Rio Grande do Norte. Advogada. Pesquisadora de pós-graduação vinculada à Base de Pesquisa em Direito e Desenvolvimento. Universidade Federal do Rio Grande do Norte - UFRN - Brasil. ORCID: https://orcid.org/0000-0003-2413-943X Lattes: http://lattes.cnpq.br/8307803806656473 E-mail: thaisileal@outlook.com
} 
Estado contemporâneo demanda novas necessidades, estas não menos importantes do que os direitos abarcados pela doutrina tradicional. Diante disso, esta pesquisa objetiva construir o conceito de direito à cidade inteligente, sob a ótica do desenvolvimento sustentável, bem como analisar o caso da Agenda Teresina 2030, especificamente no que diz respeito ao Observatório da Mobilidade. Esta pesquisa fará uso de material bibliográfico, legislação sobre o tema e estudo de caso sobre o Observatório da Mobilidade. Pode-se depreender que o direito à cidade, no formato em que é pregado atualmente, já não contempla mais a realidade social atual. Após o advento da tecnologia, e com o desenvolvimento constante desta, é urgente pensar as cidades numa perspectiva inteligente, sustentável, interconectada, funcional e inclusiva.

Palavras-chave: Direito à Cidade Inteligente; Desenvolvimento Sustentável; Agenda Teresina 2030; Observatório da Mobilidade; Blockchain.

\section{ABSTRACT}

The right to the city has been the subject of discussion for more than fifty years, which has enabled a wide debate on what are the basic rights that involve the study of this guarantee. After almost half a century, the theme has suffered a strong impact, mainly due to the innovations that have emerged in the last decades, especially after the advent of technology. In this sense, there is an urgent need to study the phenomenon of smart cities as an integral part of the right to the city, while the contemporary State demands new needs, these no less important than the rights covered by traditional doctrine. Therefore, this research aims to build the concept of the right to the smart city, from the perspective of sustainable development, as well as to analyze the case of the Teresina 2030 Agenda, specifically with regard to the Mobility Observatory. This research will make use of bibliographic material, legislation on the subject and a case study on the Mobility Observatory. It can be seen that the right to the city, in the format in which it is currently preached, no longer contemplates the current social reality. After the advent of technology, and with its constant development, it is urgent to think about cities in an intelligent, sustainable, interconnected, functional and inclusive perspective.

Keywords: Right to the smart city; Sustainable Development; Teresina Agenda 2030; Mobility Observatory; Blockchain. 


\section{INTRODUÇÃO}

O estudo do direito urbanístico contemporâneo tem encontrado novos desafios com a evolução da tecnologia, a acentuação do processo de globalização e a interconectividade proporcionada pelas Tecnologias da Informação e Comunicação (TICS).

Investigar os novos contornos e obstáculos do direito à cidade é fundamental para manter os estudos jurídico-científicos atentos às novas perspectivas. Nesse contexto, se situam as discussões que envolvem as cidades inteligentes, espaço onde cidadãos, objetos e serviços públicos se interconectam por meio das tecnologias, otimizando a qualidade de vida nos ambientes urbanos. Nas cidades inteligentes, o desenvolvimento sustentável dos cidadãos, do meio ambiente e da cidade como um todo é a pedra angular para o progresso.

Apesar de serem estudadas, difundidas, planejadas e até mesmo concretizadas há décadas, as cidades inteligentes e seus instrumentos até então não foram contempladas com profundidade pelas pesquisas que se debruçam sobre o direito à cidade.

Atualmente, é de senso comum que os indivíduos que habitam as cidades não têm garantidos os direitos básicos que compõe a teoria tradicional sobre o direito à cidade. Contudo, é urgente propor a atualização do que prega esse direito, ao passo que na era da tecnologia, onde o mundo está conectado por meio das TICs, a concepção acerca de apoderar-se da cidade, enquanto indivíduo, cidadão e habitante, deixa evidente que, atualmente, viver dignamente também é estar bem informado, incluído e conectado à cidade.

Destaque-se que o presente estudo não pretende propor a negligência das garantias básicas inerentes ao direito à cidade, mas sim sugerir a atualização, difundindo assim a agregação de novos direitos a essa teoria.

Diante disso, esta pesquisa objetiva analisar o estado da arte do direito à cidade, propor a atualização desse direito, bem como estabelecer um marco conceitual para o direito à cidade inteligente, sob a ótica do desenvolvimento sustentável, sem a pretensão de ser redundante, tampouco de discutir pontos que caberiam dentro da teoria pura do direito à cidade.

Pretende-se examinar o fenômeno das cidades inteligentes, para que seja possível compreender que, com o advento da tecnologia, novas necessidades foram incorporadas às cidades e aos indivíduos que as habitam. 
Este estudo também investigará o caso da Agenda Teresina 2030, especificamente no que diz respeito ao Observatório da Mobilidade, que, apesar de não ter a pretensão expressa de transformar o espaço municipal em uma cidade inteligente, tem adotado medidas que caminham nessa direção.

Para tanto, esta pesquisa fará uso de material bibliográfico, legislação que versa sobre o tema e estudo de caso sobre o Observatório da Mobilidade, desdobramento da agenda teresinense.

Por fim, em síntese, pode-se depreender que o direito à cidade, no formato em que é pregado atualmente, já não contempla a totalidade da realidade social atual. Após o advento da tecnologia, e com o desenvolvimento constante desta, é urgente pensar as cidades numa perspectiva inteligente, ou seja, de modo sustentável, interconectado, funcional e inclusivo.

\section{DIREITO À CIDADE INTELIGENTE}

O debate entorno do direito de acesso à cidade tem sido amplo nos últimos tempos. Isto porque este direito tem sofrido forte impacto de criações que surgiram nas últimas décadas, principalmente após o advento da tecnologia.

Inicialmente, cumpre esmiuçar o conceito de direito à cidade, bem como a definição de cidade inteligente, para que seja possível compreender por qual motivo este está contido no primeiro conceito, mas ainda assim precisa de destaque.

O direito à cidade foi uma ideia desenvolvida em meados de 1968, por Henri Lefebvre, que pregava que este direito era proveniente da demanda por um acesso renovado e transformado da vida urbana (PURCELL, 2002).

Para Lefebvre, não bastava que a cidade simplesmente existisse e permitisse que os indivíduos sobrevivessem, era essencial que o espaço e a vida urbana fossem renovados e brutalmente transformados, proporcionando assim melhor qualidade de vida para os seus habitantes.

Corroborando com isso, pode-se afirmar que o direito à cidade vai além da liberdade individual para acessar os recursos urbanos, diz respeito ao direito de mudar a si mesmo por e para mudar a cidade. Consiste em um direito coletivo, em razão de a transformação fatalmente depender do exercício de um poder coletivo para dar nova forma ao processo de urbanização. 0 
direito a fazer, refazer, construir ou modificar as cidades e os próprios cidadãos é um dos mais valiosos, e ainda assim mais negligenciados, dos direitos humanos (HARVEY, 2008).

Por meio da criação e do desenvolvimento do conceito de direito à cidade e da incorporação dele nas lutas sociais, surgiram movimentos emblemáticos em todo o mundo, a exemplo da mobilização sul-africana de moradores de barracos, conhecido como Abahlali baseMjondolo (ABAHLALI, 2019), criada para e por pessoas pobres que careciam de moradia e que reivindicavam condições melhores de habitação social.

Essa iniciativa, ainda que muito posterior à criação do conceito de direito à cidade, refletiu a evolução do pensamento do povo acerca dos seus direitos, bem como evidenciou o início de uma nova etapa de conscientização social sobre habitar, morar, viver e apropriar-se da cidade, cobrando assim condições de vida melhores, exigindo uma verdadeira transformação.

O direito à cidade no Brasil, sob a perspectiva da reforma urbana, nasceu por volta da década de 1960, com o Movimento Nacional pela Reforma Urbana (MNRU), movimento que foi interrompido no período da ditadura militar, mas que retornou com força durante o processo de redemocratização brasileiro, mais tarde, na década de 1980 (AMANAJÁS; KLUG, 2018).

Dando sequência, outro marco importante na construção da história do direito à cidade no Brasil foi a realização da Assembleia Constituinte, por meio de uma emenda popular, momento em que ocorreu a primeira conquista, no contexto dos preparativos da constituição cidadã, com a definição do Capítulo II, Título VII, da Constituição Federal de 1988, especificamente com a idealização de dois artigos, o 182 e o 183, que versam sobre a política urbana no Brasil (AMANAJÁs; KLUG, 2018), os quais até hoje figuram como marco na constituição desse direito.

O dispositivo 182 prevê que a política de desenvolvimento urbano tem por objetivo ordenar o pleno desenvolvimento das funções sociais da cidade, o que se concretiza quando atende às exigências fundamentais de ordenação da cidade, dispostas no plano diretor (BRASIL, 1988). O artigo 183 dispõe acerca dos instrumentos para promoção da regularização fundiária urbana, em especial, no que tange a possibilidade de usucapião especial de imóvel urbano (BRASIL, 1988).

Após a batalha pela regulamentação dos dispositivos constitucionais, bem como pela efetivação das funções sociais da cidade, em 2001, com a Lei Federal no 10.257, que ficou conhecida como Estatuto da Cidade, mais uma página da história do direito à cidade no Brasil foi escrita, ao passo que neste diploma foi incluído o direito à terra urbana, ao saneamento, à infraestrutura, ao transporte, aos serviços públicos, ao trabalho e ao lazer 
(AMANAJÁS; KLUG, 2018). Assim, mais direitos foram expressamente incorporados ao texto legal, permitindo que os cidadãos tivessem maiores garantias, no que diz respeito a esse assunto.

A partir disso, inúmeros outros direitos passaram a ser reivindicados dentro do contexto do direito à cidade, isto porque os cidadãos passaram a compreender que as reivindicações que surgiram junto ao conceito de direito à cidade eram garantias mínimas, eram o que de mais básico o Poder Público deveria assegurar.

A partir dos anos 2000, com o início do acesso à rede mundial de computares e com o desenvolvimento da tecnologia, a ideia tradicional de direito à cidade sofreu mudanças consideráveis.

Nesse contexto, surgiu um movimento que propunha a incorporação de tecnologia da informação e a comunicação ao planejamento urbano (GOMES; PALIOLOGO, 2017). Pensar as cidades apenas sob o prisma da mobilidade urbana, do saneamento básico e da regularização fundiária já não contemplaria mais a realidade das cidades contemporâneas, era preciso ir além, era preciso pensar numa perspectiva de globalização e, consequentemente, de realidade transfronteiriça.

Dentro dessa lógica, surgem as cidades inteligentes (smart cities), espaço onde cidadãos, objetos, serviços públicos e os demais ativos, se interconectam por intermédio das tecnologias, de modo a otimizar a qualidade de vida nos ambientes urbanos (NORTHSTREAM, 2019). As cidades inteligentes são, portanto, comunidades em que se utiliza de esforço consciente para manusear a tecnologia da informação, com o intuito de transformar a vida e trabalho das pessoas, bem como as regiões em que elas vivem, em relevantes e fundamentais, não se preocupando somente com o crescimento (CALIFORNIA INSTITUTE, 2016). Nas cidades inteligentes, o desenvolvimento dos cidadãos, do meio ambiente e da cidade como um todo é o ponto de interseção para a evolução.

Uma cidade inteligente é uma área geográfica bem definida em que as tecnologias de ponta, a exemplo das Tecnologias da Informação e Comunicação, logística, produção de energia, dentre outras, são utilizadas conjuntamente para criar uma melhoria no bem estar do cidadão, sua inclusão e participação, qualidade ambiental e desenvolvimento inteligente, através de um conjunto consolidado de indivíduos competentes para apontar regras e políticas para a cidade e para o desenvolvimento (DAMERI, 2013). Assim, a smart city é mais do que uma cidade onde os seus indivíduos usam tecnologia, é a soma dos fatores supracitados, de forma a que eles promovam o desenvolvimento. 
Por meio dos conceitos dispostos, fica evidente que as cidades inteligentes estão pautadas, principalmente, no desenvolvimento sustentável, tendo em vista que elas se preocupam com o desenvolvimento social, ambiental e econômico, de modo a satisfazer as necessidades básicas; a se pautar na solidariedade com as futuras gerações; na participação da população envolvida; na preservação do meio ambiente e dos recursos naturais; na estruturação de um sistema social que garanta emprego, segurança social e respeito a outras culturas; e em programas de educação (GALLO, 2007).

Frente ao exposto, apesar de ser evidente que os indivíduos que habitam as cidades não têm garantidos nem os direitos básicos que compõe a teoria tradicional sobre o direito à cidade, a exemplo do direito a uma cidade bem estruturada e funcional, é urgente propor a atualização do que prega esse direito. Em tempos tecnológicos, onde o mundo está conectado por meio das TICs, a concepção acerca de apoderar-se da cidade enquanto indivíduo, cidadão e habitante, deixa evidente que, atualmente, viver dignamente, bem informado, incluído e conectado à cidade demanda aparato tecnológico, bem como a oferta de um serviço que leve a web para que todos.

Inúmeros centros urbanos já se espelham no ideal de cidade inteligente para se remodelarem, o que se torna impossível sem pensar primeiramente em como garantir ao cidadão o direito à cidade inteligente.

Diante dessa realidade, surge um fenômeno associado às smart cities, um novo tipo de gentrificação relacionada com a segregação de parte da população que não possui habilidade ou conhecimento suficiente para lidar com a tecnologia. Percebe-se que este novo tipo gentrificação não tem relação com o alto custo dos imóveis ou com o custo de vida em si, mas sim com a exclusão de determinados indivíduos do processo de desenvolvimento da cidade (HOLLANDS, 2008).

Existe o perigo real de as cidades produzirem novas formas de segregação, se não estiverem alertas para valores como a cidadania, a identidade urbana e o sentimento de pertencimento. Justamente por isso a governança deve ser trabalhada para se concretizar conforme a sua teoria, de modo a ser planejada em conjunto com o direito à cidade, promovendo a inclusão política através do envolvimento dos cidadãos nas tomadas de decisão e na definição do futuro urbano (GOMES; PALIOLOGO, 2017). Ademais, isso também revela a importância dos debates entorno da construção do conceito de direito à cidade inteligente, bem como de os estudiosos passarem a considerar que esta é uma realidade atual, não que se avizinha.

Os construtores das cidades precisam ser visionários, mas também realistas (GLAESER, 2011), contemplando assim a situação específica de cada espaço, considerando os seus pontos 
fortes, mas também as suas dificuldades, de modo a evitar possíveis situações ainda mais excludentes do que as da atualidade.

Importa frisar que o direito à cidade inteligente, que se propõe nesta pesquisa, vai além de conectar o cidadão por meio da internet. Diz respeito a possibilitar o direito a uma cidade sustentável, eficiente, planejada de modo inteligente, interconectada, funcional e inclusiva, todos esses direitos básicos, mas esquecidos diante da realidade em que até os direitos expressamente fundamentais são negligenciados pelo Poder Público. Contudo, o direito à cidade nos moldes tradicionais, apesar de ainda ser preterido pelos governantes brasileiros, não inviabiliza o desenvolvimento, ou melhor, o desabrochar da teoria do direito à cidade inteligente.

Isto porque, assim como direito à moradia está para a teoria do direito à cidade, o direito à inclusão digital/tecnológica está para a ideia de direito à cidade inteligente. O mundo caminha para a direção em que o acesso ao conhecimento informacional já é e será cada vez mais fundamental para o cidadão no contexto das cidades.

Por fim, pode-se estabelecer como direito à cidade inteligente assegurar ao cidadão a conexão com os demais indivíduos e com a própria cidade, possibilitando o direito de acesso a um ambiente sustentável, eficiente, planejado de modo inteligente, interconectado, funcional e inclusivo.

\section{O DESENVOLVIMENTO SUSTENTÁVEL SOB A PERSPECTIVA DAS CIDADES INTELIGENTES}

Antes de adentrar na discussão sobre o desenvolvimento sustentável sob a ótica das smart cities é fundamental explanar o conceito de desenvolvimento, situá-lo no contexto atual, abordando as teorias que tratam sobre o tema e desvencilha-lo da ideia pura de crescimento, ao passo que, por vezes, as referidas concepções foram tratadas como sinônimos.

Diante disso, tem-se que o conceito tradicional de desenvolvimento considera fatores como crescimento do Produto Nacional Bruto (PNB), aumento das rendas pessoais, industrialização e avanço tecnológico (SEN, 2009). Contudo, diversas concepções atuais contrariam esta visão puramente econômica de desenvolvimento (LIMA; DANTAS; GUIMARÃES, 2015).

Exemplo disso é a conceituação defendida por Amartya Sen, a qual considera o desenvolvimento como meio de alcançar o Desenvolvimento Pleno, a garantia das liberdades sociais, quais sejam, garantias sociais mínimas, como a participação política, a segurança, a 
moradia, aumento de renda e a saúde pública, de modo a promover a inclusão social. Assim, o desenvolvimento deve ocorrer nos âmbitos social, ambiental e econômico, pois, ao se tornar liberto, o indivíduo se tornaria eficaz, promovendo a preservação ambiental e o próprio crescimento social (SEN, 2009). Frente a isso, pode-se concluir que o fundamento do desenvolvimento é a liberdade, a independência e a autonomia.

Comparando a visão tradicional com a percepção contemporânea, fica evidente que, atualmente, a ideia que alia o desenvolvimento puramente ao crescimento econômico perdeu força. Isto porque se entende que só é possível desenvolver progressivamente por meio da sustentabilidade. O desenvolvimento finito, ou seja, aquele que extrai, explora e usa determinados recursos para alcançar o desenvolvimento só dura certo tempo. Frente a isso, cabe questionar: pode-se afirmar que o desenvolvimento é uma ideia finita? A partir dessa observação, as teorias voltadas para o desenvolvimento sustentável ganharam força.

Adentrando na teoria do Desenvolvimento Sustentável, esta converge em parte com a supramencionada ideia de Desenvolvimento Pleno, mas não coloca em foco as liberdades sociais. Para essa teoria, o desenvolvimento deve ter como pilares os seguintes requisitos: a) satisfação das necessidades básicas; b) solidariedade com as futuras gerações; c) participação da população envolvida; d) preservação do meio ambiente dos recursos naturais; e) estruturação de um sistema social que garanta emprego, segurança social e respeito a outras culturas; e f) programas de educação (GALLO, 2007). A partir dessa concepção, pode-se depreender que o desenvolvimento sustentável deve ultrapassar o mero aumento de renda, atingindo também a garantia dos direitos básicos individuais (LIMA; DANTAS; GUIMARÃES, 2015).

Partir dessa diferenciação é essencial para que seja possível compreender que o desenvolvimento sustentável, em sua concepção mais moderna, se preocupa não apenas com índices econômicos e com questões ambientais, mas também com as necessidades do presente, com condições de vida minimamente dignas e em como as decisões que o homem toma hoje impactarão nos indivíduos no futuro.

Assim, o desenvolvimento sustentável é aquele que atende às necessidades do presente, sem comprometer a capacidade de as futuras gerações verem satisfeitas as suas próprias necessidades (ORGANIZAÇÃO DAS NAÇÕES UNIDAS, 2019). É, portanto, se auto sustentar, é se manter sem comprometer o futuro do meio ambiente, bem como todos os que dependem dele.

A proposta central da sustentabilidade é, portanto, a busca da eficiência na utilização dos recursos naturais (ACSELRAD, 2009), o que culminaria em uma espécie de desenvolvimento 
inteligente, ao passo que o consumo atual seria pensado de modo a reverberar minimamente nos indivíduos e no planeta do futuro.

A Constituição Federal de 1988 traz, em seu artigo 225, a previsão de que é direito de todos um meio ambiente ecologicamente equilibrado, bem de uso comum do povo e essencial à sadia qualidade de vida, sendo obrigação do Poder Público e da coletividade o dever de defendê-lo e preservá-lo para a geração atual e futuras (BRASIL, 1988). Tal disposição torna evidente a relevância do assunto, ao passo que o legislador se preocupou em assegurar que todos, Poder Público e coletividade, têm a obrigação legal de resguardar o meio ambiente e, consequentemente, lutar pela garantia do desenvolvimento sustentável.

Por meio da previsão constitucional acima, pode-se constatar que o constituinte verificou que o crescimento das atividades econômicas merecia um novo pacto. Não caberia mais permitir que as atividades econômicas se desenvolvessem negligenciando os fatos contemporâneos. A preservação do meio ambiente passou a ser reivindicada, ao passo que sua constante degradação implicaria na redução da capacidade econômica brasileira, não sendo possível que a geração atual, bem como as futuras, gozasse de uma vida com qualidade, caso a visão anterior a esta fosse perpetuada (FIORILLO, 2014).

Superada a conceituação de desenvolvimento, desenvolvimento sustentável e crescimento, assim como a diferenciação entre estes, cabe adentrar na importância de pensar as cidades dentro do ideal do desenvolvimento sustentável. Isto porque, os conceitos debatidos de nada adiantariam se fizessem parte apenas das teorias doutrinárias. Urge colocar em prática mecanismos que possibilitem a construção de um planeta sustentável, o que só é possível a partir de uma forte conscientização da população, bem como da atuação eficiente, planejada e participativa, promovida pelo Poder Público.

Assim, conforme construído no tópico dois, as cidades inteligentes estão pautadas, principalmente, no desenvolvimento sustentável, tendo em vista que elas se preocupam com o desenvolvimento social, ambiental e econômico.

Uma cidade inteligente é um espaço onde as pessoas e o Poder Público se articulam no sentido de tornar o ambiente público eficiente e sustentável. Na smart city, o foco é o desenvolvimento inteligente (GOMES; PALIOLOGO, 2017).

A smart city culmina em uma combinação entre sociedade, administração pública, tecnologia e planejamento urbano. Tornar a cidade mais inteligente é um propósito que está 
centrado no cidadão, que é o principal agente de transformação e que é o objetivo final das transformações urbanas (GOMES; PALIOLOGO, 2017).

Diante disso, percebe-se que é impossível pensar uma cidade inteligente afastada do viés do desenvolvimento sustentável. Isto porque, para que uma cidade seja inteligente, ser autossustentável, da perspectiva desenvolvimentista, é fundamental.

Essas cidades são projetadas com o uso inteligente de informações digitais, em domínios como saúde humana, mobilidade, energia, educação, transferência de conhecimento e governança urbana (CARAGLIU; BO; NIJKAMP, 2011). Nada existe ou ocorre nesse tipo de espaço sem ter sido planejado ou projetado.

Assim, as smart cities são compreendidas como espaços conectados através de diversas redes, que fornecem dados sobre os movimentos de pessoas e materiais em termos do fluxo de decisões sobre a forma física e social da cidade. Entretanto, as cidades só podem ser inteligentes se houver mecanismos de inteligência que sejam capazes de integrar e concatenar esses dados para algum objetivo, formas de melhorar a eficiência, equidade, sustentabilidade e qualidade de vida nas cidades (BATTY, 2012). A partir dessa análise, fica claro que não existe cidade inteligente sem estar pautada na sustentabilidade, no desenvolvimento consciente e no progresso conjunto de todos os atores envolvidos no espaço em que ela funciona.

Para ter êxito, as cidades precisam avançar, além de um modelo puramente econômico de sucesso, adotando o viés da qualidade de vida. Os seus construtores precisam ser visionários, mas também realistas (GLAESER, 2011), contemplando assim a situação específica de cada espaço, considerando os seus pontos fortes e suas dificuldades.

Em suma, é inequívoco afirmar que o desenvolvimento sustentável é um dos pilares mais importantes das smart cities, ao passo que, desenvolver sustentavelmente é desenvolver de forma inteligente, seria impossível discutir as cidades inteligentes sem tocar na perspectiva da sustentabilidade.

\section{A AGENDA TERESINA 2030 E O CASO DO OBSERVATÓRIO DA MOBILIDADE}

Após discutir o direito à cidade inteligente e o desenvolvimento sustentável no contexto desses espaços, é fundamental abordar exemplos reais, que tornem palpáveis a ideia de construir 
uma smart city, bem como de assegurar o direito à inclusão digital, tecnológica, informacional e a um desenvolvimento inteligente, portanto, sustentável.

Diante disso, antes de adentrar especificamente no caso do observatório da mobilidade, cabe abordar a Agenda Teresina 2030, iniciativa da Prefeitura de Teresina/PI, que consiste em um pacto entre Poder Público e sociedade, no que diz respeito ao planejamento e execução de metas locais para o desenvolvimento sustentável da capital (TERESINA/PI - SECRETARIA MUNICIPAL DE PLANEJAMENTO, 2019a).

A referida agenda está alinhada com os 17 Objetivos de Desenvolvimento Sustentável (ODS), trazendo um plano de metas e ações para a construção de uma cidade sustentável para as pessoas (TERESINA/PI - SECRETARIA MUNICIPAL DE PLANEJAMENTO, 2019a). Assim, a proposta traz, dentre outras, especificamente a previsão de concretização do objetivo onze, que consiste em tornar as cidades e os assentamentos humanos lugares inclusivos, seguros, resilientes e sustentáveis.

A Agenda Teresina 2030 está dividida e propõe a atuação em cinco eixos temáticos: a) Cidade Sustentável; b) Cidade de Oportunidades; c) Cidade de Direitos; d) Cidade Criativa; e e) Governança Eficiente (TERESINA/PI - SECRETARIA MUNICIPAL DE PLANEJAMENTO, 2019b).

A proposta foi elaborada com a participação de instituições públicas municipais, estaduais e federais, empresas privadas de grande responsabilidade social, organizações do chamado Terceiro Setor e entidades do movimento popular, sindical, classista, patronal, laboral e profissional (TERESINA/PI - SECRETARIA MUNICIPAL DE PLANEJAMENTO, 2019b). Diante disso, pode-se perceber que a supracitada agenda foi idealizada conjuntamente, de modo participativo, coletivo, objetivando, portanto, ouvir principalmente as necessidades da população municipal e projetando soluções pautadas nessas demandas.

Dando prosseguimento, importa mencionar que, apesar de a Agenda Teresina 2030 trabalhar em cinco frentes, esta pesquisa pretende aprofundar a discussão sobre o eixo "Cidade Sustentável", especificamente no que tange a mobilidade urbana e o transporte público.

Assim, a meta correspondente à mobilidade urbana e ao transporte público traz como ações previstas para melhorar o funcionamento destes, por exemplo, implementar centrais de serviços públicos à população, construir terminais de cargas, criar corredores de ônibus, bem como construir viadutos em cruzamentos e estender avenidas (TERESINA/PI - SECRETARIA MUNICIPAL DE PLANEJAMENTO, 2019c). 
Para que todos os objetivos idealizados possam ser executados com a integração da sociedade, de modo a unir a população, a tecnologia, a mobilidade urbana e o transporte público, no ano de 2015 foi criado o projeto "Observatório da Mobilidade: blockchain para a co-gestão do transporte público", que visa armazenar de modo digital, seguro, eficiente, em único lugar e acessível à população, todas as informações relacionadas ao transporte coletivo, a exemplo de ordens de serviço e relatórios de viagens. O foco dessa iniciativa é melhorar os serviços e aproximar a sociedade de processos de tomada de decisão na gestão pública, tornando possível uma comunicação confiável e direta (TERESINA/PI - SECRETARIA MUNICIPAL DE PLANEJAMENTO, 2019d).

O objetivo do projeto é aumentar a transparência, armazenando registros, a exemplo dos pedidos, transações, relatórios de viagens e ordens de serviço na blockchain, todos totalmente acessíveis ao público. Os dados serão permanentemente armazenados, não podendo ser alterados ou modificados sem que as modificações sejam rastreadas, colocando nas mãos da população todas as informações pertinentes à mobilidade urbana.

O Observatório consiste em uma estratégia inédita de urbanismo (TERESINA/PI SECRETARIA MUNICIPAL DE PLANEJAMENTO, 2019d), o que atraiu atenção internacional e, se executada conforme planejada, pode fazer da capital Teresina pioneira no uso da tecnologia blockchain para essa finalidade.

A supracitada tecnologia, em síntese, consiste em uma cadeia de blocos cronologicamente organizados e protegidos por um processo de resolução de fórmulas matemáticas denominadas proof-of-work (FERREIRA, PINTO e SANTOS, 2017). O encadeamento funciona pelo acréscimo de um algoritmo, intitulado de hash, resultante do bloco anterior ao bloco seguinte, fazendo com que aquele torne-se parte do resultado seguinte (FERREIRA, PINTO e SANTOS, 2017). Assim, por se tratar de uma tecnologia de construção e manipulação complexa, ela se blinda de possíveis ataques, o que a torna ainda mais segura. A ideia é tão promissora que foi selecionada pelo Fundo Europeu para o Clima, coordenado pela União Européia, e receberá o aporte de trezentos mil euros.

A blockchain é, portanto, um grande "livro contábil digital" e de gestão de dados, todos os dados inseridos no sistema não podem ser modificados, sendo possível o acesso, de qualquer indivíduo, às informações contidas nela (LIMA, 2018). Essas características fazem dessa tecnologia não só uma alternativa eficiente, mas também extremamente segura e transparente, ao passo que todas as informações ficam à disposição de qualquer um que queira acessá-las, bem como só podem ser alteradas se o possível invasor detiver cinquenta e um porcento do controle da rede, o que, em termos práticos, seria impossível. 
Pautar o desenvolvimento da cidade no tripé tecnologia, participação social e governança pública é caminhar para a aproximação do ideal de cidade inteligente, a qual consiste exatamente em utilizar de esforço consciente para manusear a tecnologia da informação com o intuito de transformar a vida e trabalho das pessoas, bem como as regiões em que elas vivem, em relevantes e fundamentais, não se preocupando somente com o crescimento (CALIFORNIA INSTITUTE, 2016).

Pode-se constatar que, concretizando o que prevê a Agenda 2030 e o projeto Observatório da Mobilidade, Teresina caminhará na direção correta para ser uma cidade inteligente, ou seja, uma cidade que investe nos capitais humanos e sociais, nos meios de transporte, de tecnologias da informação (TIC), em melhoria na infraestrutura de combustível, crescimento sustentável e em aumento na qualidade de vida, junto a uma boa gestão dos recursos naturais, tudo isso resultado de uma governança participativa (CARAGLIU; BO; NIJKAMP, 2011).

Planejar um projeto de reestruturação da cidade pautada na governança é fundamental para a implementação de produtos sólidos. Neste sentido, a governança diz respeito ao modus operandi das políticas governamentais que abarcam questões relacionadas ao modelo políticoinstitucional dos processos de decisão, à definição da mistura entre o público/privado nas políticas, à participação e descentralização, aos mecanismos de financiamento das políticas e ao alcance global dos programas. Destaque-se que o conceito não se restringe meramente aos aspectos gerenciais e administrativos do Estado, tampouco ao funcionamento eficaz do aparelho estatal (MELO, 1995).

Apesar de muitos afirmarem que governança é o mesmo que governo, cabe diferenciar que o governo sugere atividades sustentadas por uma autoridade formal, pelo poder de polícia que garante a implementação das políticas devidamente instituídas, enquanto a governança está mais ligada às atividades pautadas em objetivos comuns, que podem ou não provir de responsabilidades formais e não dependem necessariamente do poder de polícia para que sejam aceitas e prosperem frente a possíveis resistências (ROSENAU, 2000).

Partindo do referido conceito, resta evidente que o projeto Observatório da Mobilidade, a partir do uso da tecnologia blockchain, que permite o acesso aos dados, a transparência e o controle das informação que dizem respeito à mobilidade urbana, coloca o cidadão como detentor das rédeas da gestão, ao passo que ele tem acesso aos dados públicos, podendo cobrar, sugerir e questionar com mais propriedade, já que não será mais refém da boa vontade da administração pública, a qual, por vezes, não põe em prática o que dispõe os princípios da publicidade, transparência e eficiência. 
Outro ponto que deve ser considerado é que, adequando o transporte público às necessidades dos cidadãos, Teresina se coloca dentro do que prevê o desenvolvimento sustentável, o qual deve ser pautado, dentre outros requisitos, na satisfação das necessidades básicas; na participação da população envolvida; e na preservação do meio ambiente e dos recursos naturais (GALLO, 2007). Para ser inteligente e consequentemente eficiente, uma comunidade deve se preocupar principalmente com a inclusão social e com a melhoria da qualidade de vida dos seus cidadãos.

Frente ao exposto, resta evidente que a Agenda Teresina 2030 estimula iniciativas como o Observatório da Mobilidade, oportunizando que os cidadãos teresinenses vejam concretizado o direito de acesso à cidade, mais precisamente à cidade inteligente, ao passo que por meio da tecnologia, transparência e da governança participativa eles se veem contemplados em um projeto de cidade inclusiva e inteligente, que usa das tecnologias para melhorar as condições, e consequentemente, a qualidade de vida dos seus moradores.

\section{CONCLUSÃO}

Diante do que foi exposto, pode-se constatar que a teoria sobre o direito à cidade ainda não se debruçou em estudar os novos desdobramentos desse direito, ao passo que os elementos que compõe as cidades inteligentes ainda não são alvo investigação.

O advento da tecnologia foi determinante para o rompimento da perspectiva tradicionalista que envolve o direito à cidade. Negligenciar as inovações tecnológicas é fechar as portas para as infinitas garantias que os cidadãos, enquanto habitantes e detentores das cidades, devem reivindicar.

No mundo contemporâneo, é impossível falar em inclusão, desenvolvimento ou apoderamento sobre a cidade sem falar em interconectividade, comunicação e tecnologia no geral. Ignorar que o acesso às tecnologias é um instrumento importante no processo em que o indivíduo se apropria da cidade é escolher permanecer imerso em teorias que se tornaram não necessariamente ultrapassadas, mas incompletas, em razão da dinâmica social, tecnológica e urbanística.

A partir desta pesquisa foi possível estabelecer um conceito para o direito à cidade inteligente, o qual consiste em assegurar ao cidadão a conexão com os demais indivíduos e com a 
própria cidade, possibilitando o direito de acesso a um ambiente sustentável, eficiente, planejado de modo inteligente, interconectado, funcional e inclusivo.

Todos os supramencionados direitos são básicos, mas têm sido esquecidos diante de uma realidade em que até mesmo os direitos expressamente fundamentais são negligenciados pelo Poder Público. Contudo, o fato de o direito à cidade ainda ser preterido pelos governantes brasileiros não inviabiliza o desenvolvimento, ou melhor, o desabrochar da teoria do direito à cidade inteligente.

Dando seguimento, pode-se construir, por meio dos conceitos difundidos por vários autores, uma concepção acerca de desenvolvimento sustentável, que é, portanto, aquele que atende às necessidades do presente, sem comprometer a capacidade de as futuras gerações atenderem às suas próprias necessidades. Assim, é se auto sustentar, é se manter sem comprometer o futuro do meio ambiente, bem como sem afetar todos os que dependem dele.

Pode-se concluir que o desenvolvimento sustentável é um dos pilares mais importantes das smart cities. Ao passo que desenvolver sustentavelmente é desenvolver de forma inteligente. Seria impossível discutir as cidades inteligentes sem tocar na perspectiva da sustentabilidade.

No que diz respeito à análise do caso da Agenda Teresina 2030, esta consiste em uma iniciativa da Prefeitura de Teresina/PI, um verdadeiro pacto entre Poder Público e sociedade, no que diz respeito ao planejamento e execução de metas locais para o desenvolvimento sustentável da capital. Já o Observatório da Mobilidade: blockchain para a co-gestão do transporte público, é uma iniciativa que visa armazenar de modo digital, seguro, eficiente, em único lugar e acessível à população, todas as informações relacionadas ao transporte coletivo, a exemplo de ordens de serviço e relatórios de viagens. O foco dessa iniciativa é melhorar os serviços e aproximar a sociedade de processos de tomada de decisão na gestão pública, tornando possível uma comunicação confiável e direta.

O objetivo do Observatório da Mobilidade é aumentar a transparência, armazenando registros, a exemplo dos pedidos, transações, relatórios de viagens e ordens de serviço na blockchain, todos totalmente acessíveis ao público. Os dados serão permanentemente armazenados, não podendo ser alterados ou modificados sem que as modificações sejam rastreadas, colocando nas mãos da população todas as informações pertinentes à mobilidade urbana.

O estudo da Agenda Teresina 2030 e, especificamente, do Observatório da Mobilidade permite tornar palpável a ideia de que quando uma cidade fundamenta seu planejamento no tripé 
tecnologia, desenvolvimento sustentável, participação social e governança pública, ela caminha para a aproximação do ideal de cidade inteligente, que culmina na melhoria da qualidade de vida de seus moradores.

Por fim, pode-se perceber que se cidades com iniciativas como a de Teresina/PI já caminham no sentido de idealizar seus próximos passos nos moldes de uma cidade inteligente, urge que as pesquisas jurídico-científicas se debrucem em analisar o direito à cidade sob a perspectiva das cidades inteligentes e de seus instrumentos, sob pena de não conseguirem acompanhar de perto a evolução da população, do Poder Público e da própria cidade.

\section{NOTAS}

Apesar do Observatório da Mobilidade ter sido idealizado em 2015, o projeto ainda se encontra em fase de pré-execução, segundo têm noticiado os sítios institucionais da Prefeitura de Teresina/PI.

Contudo, cabe refletir que os dados futuramente coletados por meio da supracitada iniciativa, se trabalhados no meio acadêmico, podem culminar em ricos frutos científicos, os quais certamente serão capazes de apontar quais são as melhorias necessárias para atender satisfatoriamente a população teresinense.

Além disso, os referidos dados podem servir como base para planejamentos futuros, ao passo que permitirão que o Poder Público monitore a cidade e perceba melhor a realidade social, reavaliando assim, com maior eficiência e transparência, o que precisa ser mudado.

Por fim, é fundamental informar que a partir deste estudo pode-se constatar que não existe nenhuma outra iniciativa concreta no Poder Público brasileiro que, utilizando da tecnologia blockchain, objetive a melhoria da mobilidade urbana, como é a proposta do Observatório em questão.

\section{REFERÊNCIAS}

ABAHLALI. Abahlali baseMjondolo. Disponível em: <http://abahlali.org/node/9405/>. Acesso em: 23 dez. 2019. 
ACSELRAD, Henri. A Duração das Cidades: Sustentabilidade e Risco nas Políticas Urbanas. 2. ed. Rio de Janeiro: Lamparina, 2009. 256 p.

AMANAJÁS, Roberta; KLUG, Leticia. Direito à Cidade, Cidade, Cidades para Todos e Estrutura Sociocultural Urbana. In: COSTA, Marco Aurélio; MAGALHÃES, Marcos Thadeu Queiroz; FAVARÃO, Cesar Bruno. A Nova Agenda Urbana e o Brasil: insumos para sua construção e desafios a sua implementação. Brasília: Ipea, 2018. Cap. 2. 140 p.

BATTY, M. et al. Smart cities of the future. The European Physical Journal Special Topics, [s.l.], v. 214, n. 1, p.481-518, nov. 2012. Springer Science and Business Media LLC.

http://dx.doi.org/10.1140/epjst/e2012-01703-3. 482 p.

BRASIL, Constituição Federal de 1988. Institui a Carta Magna.

CALIFORNIA INSTITUTE. Concept. Disponível em: <http://smartcommunities.org/concept.php>. Acesso em: 20 ago. 2016.

CARAGLIU, Andrea; BO, Chiara del; NIJKAMP, Peter. Smart Cities in Europe. Journal Of Urban Technology, [s.I.], v. 18, n. 2, p.65-82, abr. 2011. Informa UK Limited. http://dx.doi.org/10.1080/10630732.2011.601117. 114 p.

DAMERI, Renata Paola. Searching for Smart City definition: a comprehensive proposal. International Journal Of Computers \& Technology, Punjab (Índia), v. 11, n. 5, p. 2544-2551, 25 out. 2013.

FERREIRA, Juliandson Estanislau; PINTO, Filipe Gutemberg Costa; SANTOS, Simone Cristiane dos. Estudo de Mapeamento Sistemático sobre as Tendências e Desafios do Blockchain. Gestão.org, [s.I.], v. 15, n, p.108-117, 31 dez. 2017. ANPAD. http://dx.doi.org/10.21714/1679-18272017v15ed.

FIORILLO, Celso Antônio Pacheco. Curso de Direito Ambiental Brasileiro. 13. ed. São Paulo: Saraiva, 2014, 159 p.

GALLO, Zildo. Ethos, a grande morada humana: economia, ecologia e ética. Itu: Ottoni, 2007. 130 p.

GLAESER, Edward L. Os Centros Urbanos: A maior Invenção da Humanidade. Rio de Janeiro: Elsevier, 2011. 360 p.

GOMES, Daniel Machado; PALIOLOGO, Nicholas Arena. Direito à cidade e políticas públicas para a smart city. Revista de Direito Urbanístico, Cidade e Alteridade, Florianópolis, v. 3, n. 1, p.19-35, jun. 2017.

HARVEY, David. The right to the city. New Left Review, Londres, v. 2, n. 1, p.23-40, set. 2008.

HOLLANDS, Robert G. Will the real smart city please stand up? City, [s.I.], v. 12, n. 3, p.303-320, 26 nov. 2008. Informa UK Limited. http://dx.doi.org/10.1080/13604810802479126.

LIMA, Gabriel Maciel de; DANTAS, Thomas Kefas Sousa; GUIMARÃES, Patrícia Borba Vilar. Patentes Sociais: A Importância da Criação de Tecnologias Voltadas a Inclusão Social e a Priorização da Concessão Dessas Patentes. 6th International Symposium On Technological Innovation, [s.I.], v. 1, n. 1, p.1-7, 25 set. 2015. Universidade Federal do Sergipe. 
LIMA, Gabriel Maciel de. A utilização das criptomoedas no âmbito nacional: um estudo dos impactos constitucionais da desconsideração das moedas virtuais no Brasil. 2018. 58 f. TCC (Graduação) - Curso de Direito, Universidade Federal do Rio Grande do Norte, Natal, 2018.

MELO, Marcus André B. C. de. (1995), Ingovernabilidade: Desagregando o Argumento. In: L. Valladares (org.), Governabilidade e Pobreza. Rio de Janeiro, Ed. Civilização Brasileira.

NORTHSTREAM. White paper on revenue opportunities. Disponível em: <http://northstream.se/white-paper/archive>. Acesso em: 20 dez. 2019.

ORGANIZAÇÃO DAS NAÇÕES UNIDAS (Estados Unidos da América). A ONU e o Meio Ambiente. 2019. Disponível em: <https://nacoesunidas.org/acao/meio-ambiente>. Acesso em: 30 dez. 2019.

PURCELL, Mark. Excavating Lefebvre: The right to the city and its urban politics of the inhabitant. Geojournal, Special Issue: Social Transformation, Citizenship, And The Right To The City, Ohio, v. 1, n. 1, p.99-108, out. 2002.

ROSENAU, James N. Governança, Ordem e Transformação na Política Mundial. In: Rosenau, James N. e Czempiel, Ernst-Otto. Governança sem governo: ordem e transformação na política mundial. Brasília: Ed. Unb e São Paulo: Imprensa Oficial do Estado, 2000. p. 436.

SEN, Amartya. Desenvolvimento como liberdade. São Paulo: Companhia das Letras, 2009. 464 p.

TERESINA/PI - SECRETARIA MUNICIPAL DE PLANEJAMENTO. Agenda 2030 Teresina. 2019. Disponível em: <https://agenda2030.carto.com/me>. Acesso em: 30 dez. 2019a.

TERESINA/PI - SECRETARIA MUNICIPAL DE PLANEJAMENTO. Agenda 2030. 2019. Disponível em: $<$ https://semplan.teresina.pi.gov.br/agenda-2030-lancamento/>.>. Acesso em: 23 dez. 2019b.

TERESINA/PI - SECRETARIA MUNICIPAL DE PLANEJAMENTO. Agenda 2030 Teresina - Metas da Agenda. 2019. Disponível em: <https://semplan.teresina.pi.gov.br/metas-agenda >. Acesso em: 30 dez. 2019c.

TERESINA/PI - SECRETARIA MUNICIPAL DE PLANEJAMENTO. Teresina será pioneira no mundo no uso de Blockchain no transporte público. 2018. Disponível em:

$<$ https://semplan.teresina.pi.gov.br/2018/05/10/teresina-sera-pioneira-no-mundo-no-uso-deblockchain-no-transporte-publico/\#comments>. Acesso em: 23 dez. 2019d.

Trabalho recebido em 23 de março de 2020

Aceito em 14 de março de 2021 